\title{
An Analysis of the Role of SMEs in Economic Development
}

\author{
Cristinel Constantin \\ cristinel.constantin@,unitbv.ro \\ Transilvania University of Brasov, Brasov, Romania
}

\begin{abstract}
The SMEs are usually considered in literature as determinants of economic development. Such companies are often put in relationship with entrepreneurship and innovation, which are among the main goals at the EU level. Our study starts from this research problem consisting in the opportunity to develop SMEs in order to reach economic development in Romania. The results reveal a strong correlation between the SMEs number and the GDP evolution but also the turnover of SMEs has to be considered. These results confirmed some theories addressed in the literature, regarding the role of business actors, public administration and education institutions in economic development.
\end{abstract}

Keywords: SMEs, GDP analysis, economic development, correlation coefficients, economic crisis, entrepreneurship

JEL Code: A11, A23, M13, M21

\section{Introduction}

The economic development is considered a priority of the entire world because it can assure the nations' prosperity. In this respect, the concept of economic development includes both economic growth and improving the population's living standards through fair incomes, economic opportunities, safety etc. [18]. In the economy of a country the Small and Medium Enterprises (SMEs) play an important role in satisfying the above conditions. At the level of European Union (EU) the SMEs are considered the "engine of the economy" as they are the most important generator of new jobs and added value [16]. The SMEs are also considered an important factor of international business development since they compete in the global market [15].

According to the EU documents, an enterprise could be included in this category if it has less than 250 persons employed and which has a turnover no more than EUR 50 million or the annual balance sheet not exceed EUR 43 million. Nevertheless only the staff number is mandatory and an enterprise can exceed one of the other requirements without to be included in the category of large enterprises [16]. Such small dimensions of these enterprises offer them a higher flexibility to innovate, to find new business opportunities or new markets in comparison with large companies. But they could be also vulnerable in critical situations or in time of economic crisis.

Starting from the above mentioned issues regarding the SMEs, we put in practice a research with the main aim to identify the role of such enterprises in the economic development of Romania. In this research we considered secondary data published by the Romanian National Institute of Statistics [17] and data analyses were computed having in mind two research questions: (1) which are the evolutions of Romania's GDP, number of enterprises and enterprises' turnover during the last years? (2) which is the correlation between the number of SMEs and the GDP?

The results show that the analyzed indicators have the same patterns of evolution and the correlation between the number of SMEs and GDP is very strong excepting the crisis period. These results reveal that SMEs play an important role in the economic development.

The article is structured as follows: Section 2 presents a short review of the specialty literature, followed by the research methodology (Section 3), results and discussion (Section 4) and conclusions (Section 5). 


\section{Literature review}

The role of SMEs in the economic development is underlined in literature but they usually need support from authorities in order to avoid market failures or other type of barriers like access to finance, knowledge, labor and other resources. Nevertheless, this support should encourage the development of a competitive environment which offers equal chances to enterprises that activate on a certain market [16]. Another incentive of SMEs development is the innovative entrepreneurship, which can help the enterprises to achieve organic growth by innovation in various fields of activity [12]. In fact, the entrepreneurship, which is associated with establishing a new business, is considered the engine of growing the number of SMEs and their contribution to the economic development $[8,13]$. In turn, the level of entrepreneurship development depends mainly on two factors: entrepreneurial tradition and entrepreneurial education [13]. This means that even if the tradition is not very strong, the entrepreneurship could be sustained by a proper education. Certain skills and competences could be created through education in order to prepare the graduates for changes in economy and in the future society [4]. In order to reach this objective the innovation has to be placed at the core of entrepreneurial education [6].

As regards the role of SMEs in economic development, studies conducted in different countries reveal a high contribution of these firms to the national GDP and labor market but the level of contribution varies from country to country even on the same continent [14]. Such differences are mainly due to the local specific, access to professional services, infrastructure and resources, which make difficult a global analysis of the SMEs role in economy [2, 3]. A study about the role of SMEs in Turkish economy shows that after the crisis the number of this type of companies remain the same but the ratio of value added decreased significantly [5]. In developing economies, such as the former communist countries, the SMEs also play an important role underlined in the specialty literature. A study made in Slovakia reveals that the countries with a large level of SMEs development have higher stability and living standards [10]. Other economies with a high speed of growth, like Albania, benefit from the large scale development of SMEs [7]. In Romania, previous studies also emphasized the high contribution of SMEs to the GDP in spite of difficulties faced by these companies [1]. Even if they were the most affected by the economic crisis, the necessity to reinforce SMEs in order to attain a high level of economic development has pointed in some researches' results [9]. This kind of results is also supported by findings in other developing economies facing with different contexts and problems, like Pakistan, Nigeria etc. [11, 14].

Taking into account the findings mentioned in literature, our research goal was to identify the relationship between the evolution of SMEs and the economic growth in Romania during the last ten years.

\section{Methods}

In order to obtain answers to the research questions stated in the introductive section, an exploratory research has been conducted based on secondary data. The main objectives established in accordance with these questions are: (1) To identify the tendencies in the evolutions of GDP, number of enterprises and turnover of enterprises during the last decade; (2) to compute the correlation between the evolution of GDP and the number of SMEs during the last decade.

The secondary data have been collected from the official statistics published by the Romanian National Institute of Statistics, which can be found on line at the following web address: http://statistici.insse.ro:8077/tempo-online/\#/pages/tables/insse-table). At the moment of this research data were available only till year 2017 so that a period of ten years has been considered (2008-2017). This period also includes the economic crisis, which started in 2008 but had effects on medium time. The first variable analyzed was the evolution of GDP in the national currency. In order to obtain comparable values, we started from the actual value 
recorded in 2017 and all other annual values have been corrected by using the Price index recorded in 2017 towards every analyzed year. The same procedure was applied for the turnover recorded by the enterprises, which was another variable analyzed. The evolution of the number of enterprises divided in categories according the company size (calculated in relation with the number of employed persons) has also been analyzed. The following categories of enterprises have been considered: microenterprises (0-9 employed persons); small enterprises (10-49 employed persons); medium enterprises (50-249 employed persons) and large enterprises (250 employed persons and more). The first three categories are considered SMEs. In order to reach the second research objective the correlation between GDP and the number of SMEs has been represented by using a scatterplot. After that, the correlation coefficients (Pearson, Kendall and Spearman) have been calculated after the elimination of years the most affected by economic crisis (2008 and 2009). In order to calculate the above mentioned coefficients, the SPSS system has been used.

\section{Results and discussions}

The evolution of GDP in Romania in the last decade (in constant prices reported to the year 2017) shows an increasing trend, which was affected by the economic crisis starting with 2009 until 2011 (see Fig. 1). In this period of time the GDP decreased significantly, with more than 10\%. After 2011, a slight increasing has been recorded annually but only in 2015 the value of GDP exceeded the level recorded in 2008. The pattern of the curve presented in Fig. 1 shows an economic growth, which might be explained by the development of local companies both as number of enterprises and their turnovers.

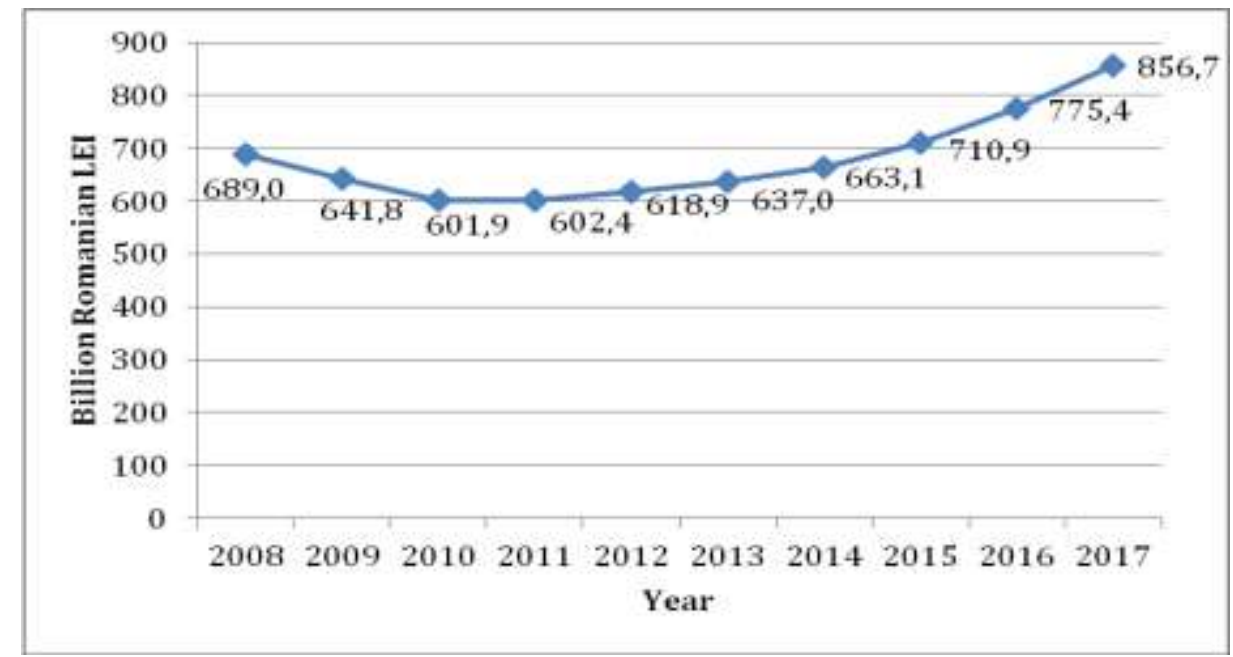

Fig. 1. The evolution of GDP in Romania between 2008 and 2017 in constant prices $(2017=1)$

(Data source: http://statistici.insse.ro:8077/tempo-online/\#/pages/tables/insse-table)

The analysis of the enterprises number according to their size, depending on the number of employed persons, shows the same pattern but the evolution of every category is quite different from another (see Fig. 2). During the last decade only the number of small enterprises (with 10-49 employed persons) exceeded the number recorded in 2008. For the other categories even if their number increased year by year, the number of enterprises in 2017 has been still smaller than in 2008 . We can see that the microenterprises (companies with less than 10 employed persons) were the most affected by the economic crisis. Thus their number decreased with more than 100000 firms between 2008 and 2011 but after this year it was recorded a fast increasing of this number, which seems to be correlated with the economic growth. 


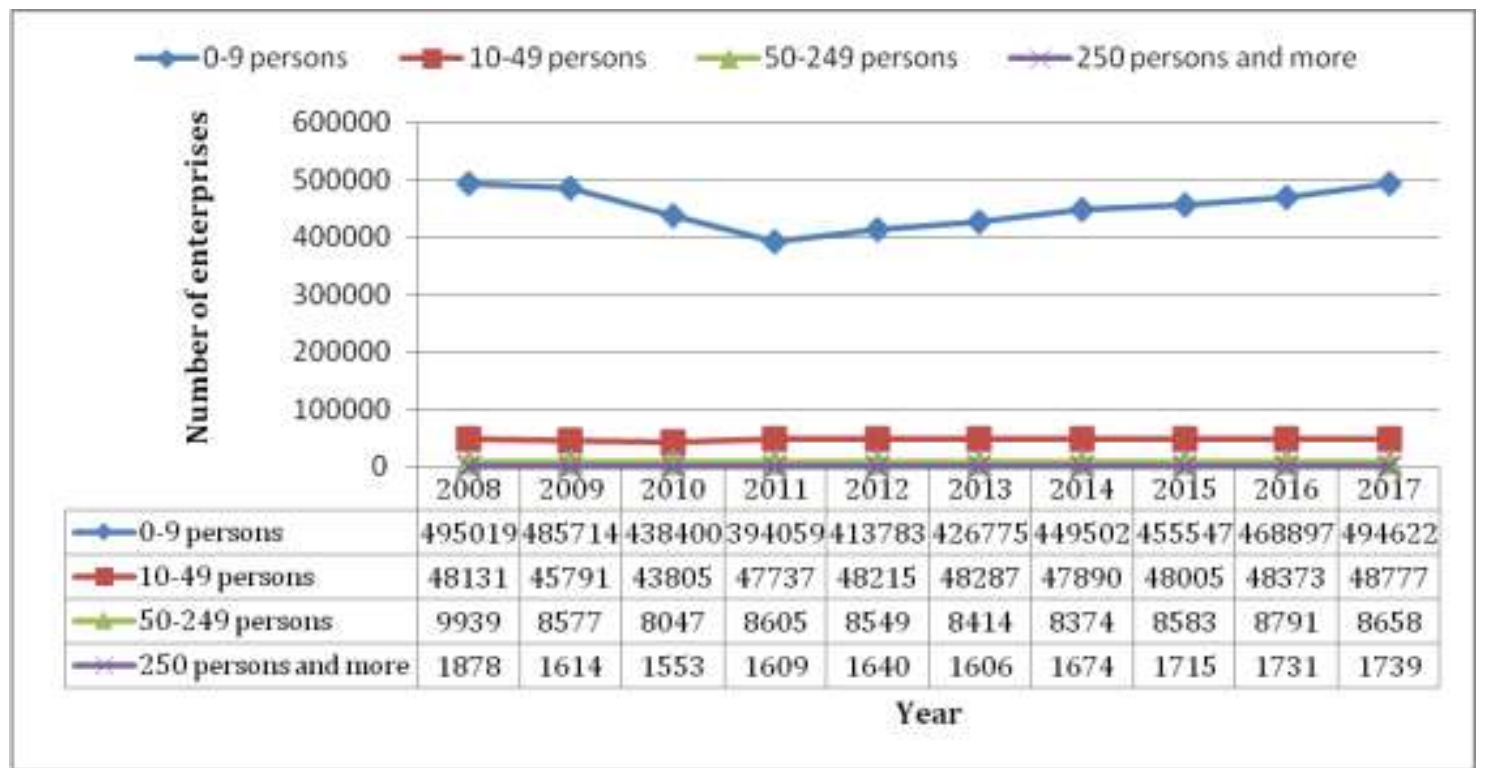

Fig. 2. The number of active enterprises in Romania by size between 2008 and 2017

(Data source: http://statistici.insse.ro:8077/tempo-online/\#/pages/tables/insse-table)

As regards the turnover recorded by enterprises during the same period of time, the evolution has been slightly different (see Fig. 3). The large companies recorded the highest decreasing in 2009 compared with 2008 but since 2010 their turnover has started the recovery. For the rest of enterprise categories the decreasing continued in 2010 and the recovery has only started since 2011. We can notice higher values for the turnover recorded by large enterprises in comparison with the other categories. But the sum of turnovers recorded by SMEs is considerably higher than the one of large enterprises. Thus in 2017 the total turnover obtained by SMEs was of Romanian Lei 934.1 billion, which was 2.23 times higher that the large enterprises' turnover. These results underline the crucial importance that SMEs have in the economic growth but also in the employment rate, which can contribute to a sustainable economic development.

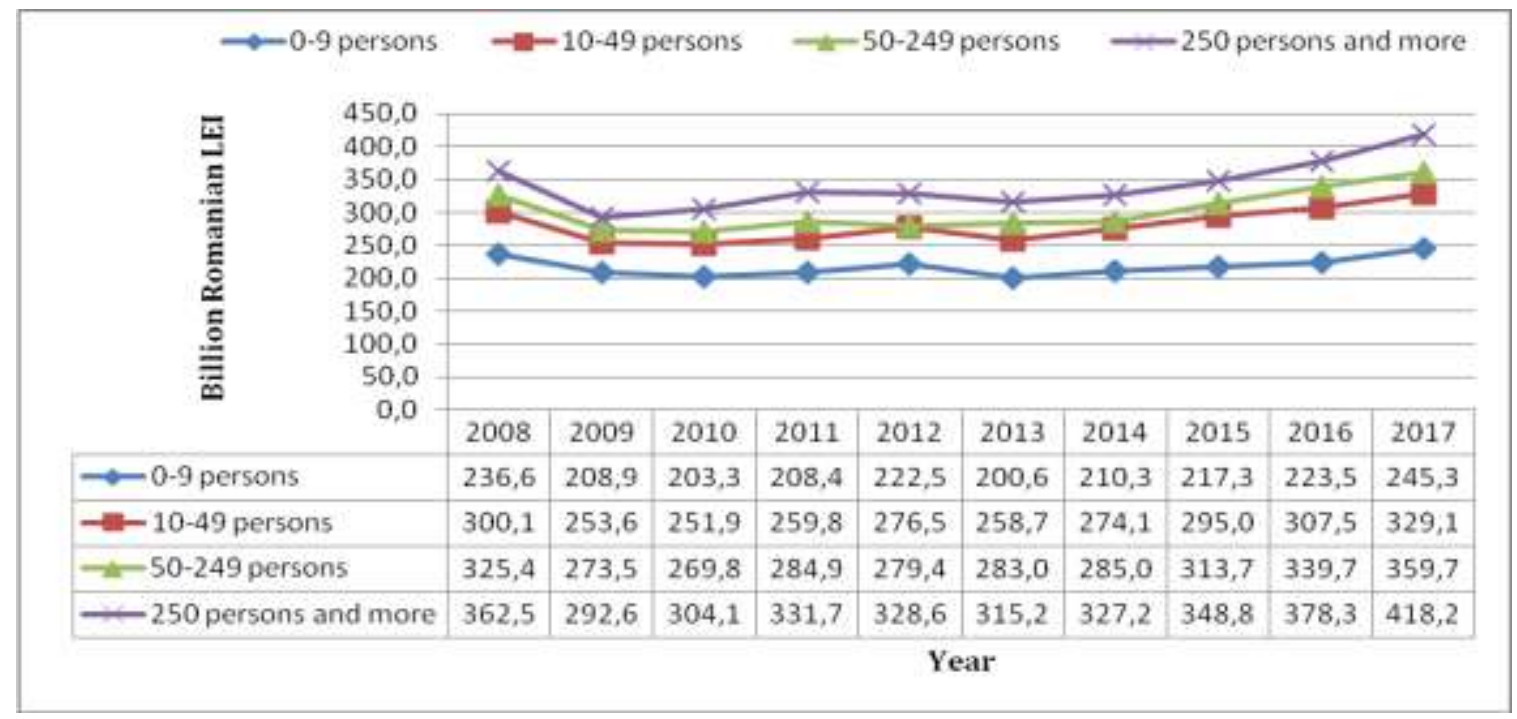

Fig. 3. The evolution of Romanian companies turnover between 2008 and 2017 in constant prices $(2017=1)$

(Data source: http://statistici.insse.ro:8077/tempo-online/\#/pages/tables/insse-table)

The results of the above analyses reveal a possible relation between the number of SMEs and the evolution of GDP in constant prices. In this respect we analyzed the correlation between the number of SMEs and the values of GDP recorded in the period 2008-2017. A scatterplot 
with the values of these two variables has been computed in Fig. 4, which reveal a direct correlation between these variables. Thus, an increasing in number of SMEs corresponds with a similar increasing in GDP. Nevertheless, there are some outliers, which are marked in Fig. 4.

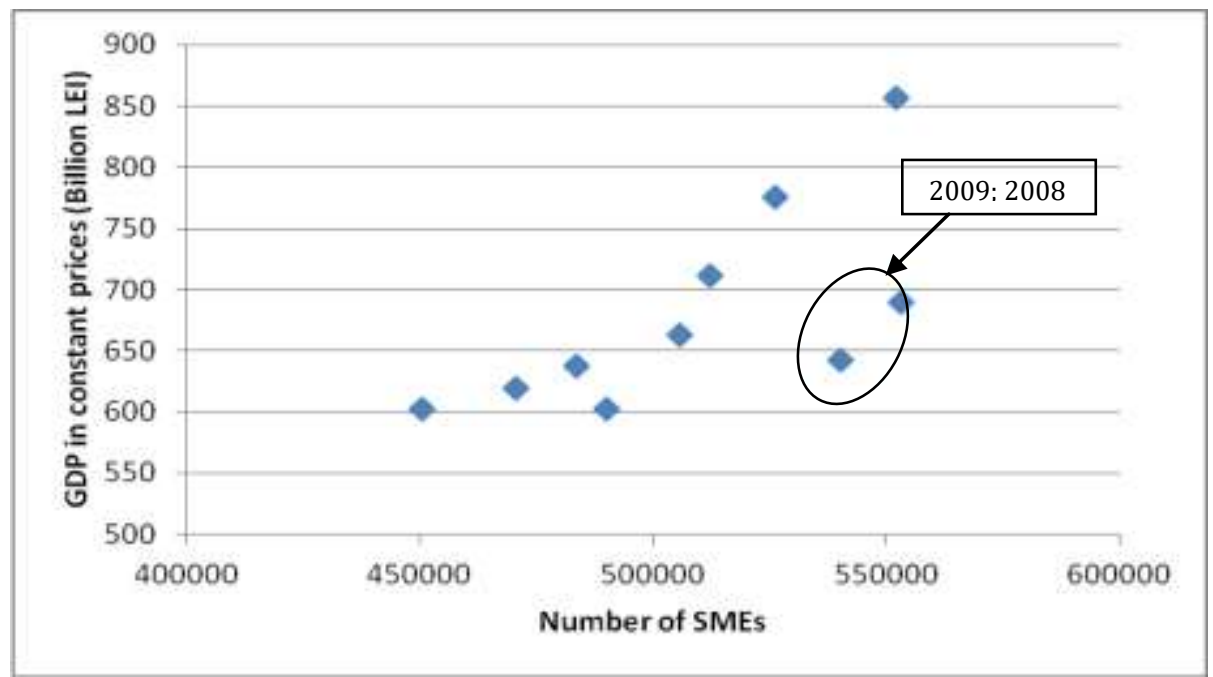

Fig. 4. The correlation between the number of enterprises and GDP in the period 20082017

(Data source: http://statistici.insse.ro:8077/tempo-online/\#/pages/tables/insse-table)

As we can see, in 2008 and 2009 the number of SMEs was quite large, but the values of GDP were modeste. Similar values of GDP have been obtained in the next years with a lower number of enterprises. These results also emphasize the importance of enterprise performance in economic growth not only the number of companies. As a conclusion, one can notice that the average performance of the Romanian companies that survived the economic crisis has increased significantly. After the crisis, the correlation between the number of SMEs and GDP is a direct and linear one. We eliminated the outlier years (2008 and 2009) from the correlation analysis because they distort the reality. By computing the Pearson correlation coeficient for the period 2010-2017, a value of 0.922 (with $\mathrm{p}<0.01$ ) has been obtained, which reveals a very strong correlation. Other correlation coefficients also return high values: Kendall's tau coeficient $(0.786)$ and Spearman's rho $(0.857)$ both with $\mathrm{p}<0.01$. These values confirm the strong relationship existing between the number of SMEs and GDP but these relationship should be considered with caution because not only the number of companies is important but also their performance.

\section{Conclusions}

As we can notice from the above analyses, all variable considered have almost the same shape of evolution curves. This shape is characterised by a strong decreasing after the year 2008 and a slight recover starting with 2010-2011. Nevertheless every variable has its own evolution which differs from the others. But as a common characteristic we can notice that the levels recorded in 2008 was very hard attained, mainly after the year 2015.

Starting from the research results we have found answers to the research questions, which are presented as follows:

\section{the last years?}

(1) which are the evolutions of Romania's GDP, number of enterprises and enterprises' turnover during

Looking at the evolution of the GDP, we can observe that after a strong decreasing in 2009 and 2010, the increasing trend has been re-launched but with significantly modest values in comparison with 2008. In fact, this value was exceeded only after 2015, which reveal a very slow recovery. In the same period of time, the active enterprises also suffered from a hard decreasing in their number. A lot of companies failed, mainly microenterprises and the number of new birth companies could not compensate the number of enterprises that leaved the market. In spite of 
the constantly increasing in the number of active enterprises recorded in the last years of the analyzed period, the total number of enterprises (both SMEs and large companies) was smaller in 2017 than in 2008. With these figures in mind, one can notice that the performance of active companies has increased in average after the crisis because their total turnover was higher in 2017 than in 2008 in comparable prices. But we also have to underline that the level of turnover recorded in 2008 has been exceeded only in 2016, when the difference compared with the starting value (year 2008) was very small. As a conclusion regarding this answer we can notice that there is a correlation between the economic growth and the enterprises activity, both regarding the enterprises number and their performance. These results confirm the theories mentioned in other articles regarding the importance of SMEs contribution in increasing GDP $[1,3,5,9,10$, and 11].

(2) which is the correlation between the number of SMEs and the GDP?

The answer to the first question indicates a direct relationship between the analyzed variables, which is intuitively extracted from their evolution patterns. In order to have a statistical image of this correlation, a scatterplot of the paired values recorded by the GDP and the number of SMEs in the analyzed period was computed. We can notice a lag of this relationship in the crisis period. Thus, even if the GDP decreased significantly in the period 2008-2009 the number of SMEs remained still high. For this reason, the values recorded in these years have been excluded from the analysis as they could be considered outliers. The rest of the years are characterized by a strong correlation of the two variables, which also stressed the importance of SMEs on economic growth. This relationship could be considered statistically significant $(\mathrm{p}<0.01)$.

As a general conclusion, we have to state that the answers to the research questions confirm a hypothesis meet in the specialty literature regarding the crucial role played by these companies in the economic growth. This hypothesis is also supported by a higher sensitivity of SMEs to different environment factors than big enterprises. These results have implication both for business environment and central and local administration, being of help in their efforts to design public policies meant to reach economic development. They also have academic implications serving for sustaining of certain theories regarding the economic development.

The present research has also some limits as the findings are focused mainly on economic growth without a specific focus on the people living standard. The further research directions should also be focused on including the above mentioned relationship into a regression model along with other variables. Such an analysis could put in evidence the real influence that every factor has on the economic development, not only a simple correlation between two variables. Nevertheless, the present results reveal that SMEs should receive a depth attention from all stakeholders: government, economic agents and education institutions, especially the higher education. This last category of stakeholders could focus its mission on developing the entrepreneurship education of students, which can lead to a strong increasing in the number and performance of SMEs in the economic context. Besides these considerations, the role of large companies should not be minimized as far as such companies are the most important partner of SMEs. Large companies often buy goods and services from SMEs as result of outsourcing various activities from their current business. In this respect the large companies have a high contribution to the SMEs development.

\section{Acknowledgement}

This work was supported by a grant of the Romanian Ministry of Research and Innovation, CCCDI - UEFISCDI, project number PN-III-P1-1.2-PCCDI-2017-0800 / 86PCCDI/2018 FutureWeb, within PNCDI III. 


\section{References}

1. Aceleanu, M. I., Traşcă, D.L. \& Şerban, A. C. (2014), The role of small and medium enterprises in improving employment and in the post-crisis resumption of economic growth in Romania, Theoretical and Applied Economics, 1(590), 87-102.

2. Anton, C. E. \& Trifan, A. (2011), Opinions of the managers of the SMEs in Brasov concerning the need of accounting information offered by the companies that provide accounting services', Bulletin of the Transilvania University of Brasov. Economic Sciences. Series V: Economic Sciences, 4 (2), 181-186.

3. Bello, A., Jibir, A. \& Abmed, I. (2018), Impact of small and medium scale enterprises on economic growth: evidence from Nigeria. Global Journal of Economics and Business, 4(2), 236-244.

4. Gautam, M. K. \& Singh, S. K. (2015), Entrepreneurship education: concept, characteristics and implications for teacher education, International Journal of Education, 5(1), 21-35.

5. Karadag, D. H. (2016), The role of SMEs and entrepreneurship on economic growth in emerging economies within the post-crisis era: an analysis from Turkey, Journal of Small Business and Entrepreneurship Development, 4(1), 22-31.

6. Kirby, D. (2004), Entrepreneurship education: can business schools meet the challenge? Education+Training, 46 (8/9), 510-519.

7. Kruja, A. D. (2013), The Contribution of SMEs to the economic growth (Case of Albania). EuroEconomica, 1(32), 55-67.

8. Kuckerta, A. \& Wagner, M. (2010), The influence of sustainability orientation on entrepreneurial intentions - Investigating the role of business experience. Journal of Business Venturing, 25 (5), 524-539.

9. Man, M. \& Macris, M. (2014), Analysis of the SMEs development in Romania in the current European context affected by the global economic crisis, Procedia Economics and Finance, 15, 663-670.

10. Mrva, M. \& Stachová, P. (2014), Regional development and support of SMEs - How university project can help, Procedia - Social and Behavioral Sciences, 110, 617-626.

11. Otugo N. E., Edoko T. D. \& Ezeanolue U. S. (2018), Effect of small and medium enterprises on economic growth in Nigeria, Sumerian ₹ Journal of Business Management and Marketing, 1(2), 73-78.

12. Szabo, Z. K. \& Herman, E. (2012), Innovative entrepreneurship for economic development in EU, Procedia Economics and Finance, 3, 268-275.

13. Toma, S. G., Grigore, A. M. \& Marinescu, P. (2014), Economic development and entrepreneurship, Procedia Economics and Finance, 8, 436-443.

14. Zafar, A. \& Mustafa, S. (2017), SMEs and its role in economic and socio-economic development of Pakistan. International Journal of Academic Research in Accounting, Finance and Management Sciences, 7(4), 195-205.

15. Edinburgh Group (2012), Growing the global economy through SMEs, http://wnw.edinburghgroup.org/media/2776/edinburgh_group_research_-_growing_the_global_economy_through_smes.pdf, Accessed on May 2019.

16. European Commission (2015), User guide to the SME definition, bttps:/ / ec.europa.eu/docsroom/ documents/15582, Accessed on May 2019.

17. National Statistics Institute, Database Tempo online, http://statistici.insse.ro:8077/tempoonline/\#/pages/tables/insse-table, Accessed on May 2019.

18. World Economic Forum. The Inclusive Growth and Development Report 2017. January 2017. 